\title{
Clinical Profile in Patients of Organophosphorous Poisoning
}

\author{
Dr Manisha Panchal ${ }^{1}$, Dr Dipti Trivedi ${ }^{2}$
}

\begin{abstract}
Aim: To study the clinical profile and correlation between acetylcholinesterase level in the patients of organophosphorous poisoning in reference to outcome. Method: 100 patients of organophosphorus poisioning were taken of age above 12 years, irrespective of sex. All patient underwent detailed clinical examination .lab investigation of serum cholinesterase level were done. Their progress and ventilator support was considered as and when required. Observation: it was observed that low serum cholinesterase level has highest requirement of ventilator support and mortality. More the time lag, higher is the risk of ventilator requirement and higher mortality. Lesser the pupil size higher is mortality. Conclusion: Organophosphorous poisoning is one of the most common cause of mortality among young adults. Early identification of signs and clinical examination along with lab investigation like serum cholinesterase level will help to prevent mortality. Timely use of mechanical ventilator can also save life.
\end{abstract}

Keywords: ventilator, miosis, acetylcholinesterase, timelag, respiratory depression

\section{Introduction}

Organophosphorous compounds are used worldwide in agriculture as well as in house and domestic insecticides. This easy availability of the compounds has resulted in increase in accidental and suicidal poisoning mainly in developing countries ${ }^{1}$.The worldwide mortalities and chronic illness due to pesticide poisoning number about 1 million per year. Organophosphorous compounds are responsible for the maximum (73\%) among them ${ }^{3}$.The mortality rate of organophosphorous poisoning is high 4 . The leading cause of death in organophosphorous poisoning is respiratory failure, which results from combination of respiratory muscle weakness, central respiratory depression, increased bronchial secretions, bronchospasm and pulmonary edema ${ }^{4}$.The present study was undertaken to identify the factors which helped in predicting the need for ventilator support, monitoring and outcome of the patients.

\section{Aim}

To study the clinical profile and correlation between acetylcholinesterase level in the patients of organophosphorous poisoning in reference to outcome.

\section{Material \& Methods}

The present study was carried in New Civil Hospital, Surat during the period of Jul'2005 to Aug'2006. 100 patients of organophosphorous poisoning admitted to our hospital were included in the study.

Patients were selected irrespective of sex. The age group included were above 12 years. Patients with other associated illness or conditions likely to accentuate the respiratory failure were excluded from the study. Patients with multiple agent poisoning are also excluded. A provisional diagnosis of organophosphorous poisoning was made on the basis of history, examination of container and typical clinical features. Serum acetylcholinesterase level was measured. Normal values of laboratory were between 3000-6000 IU/lit. According to classification of severity of poisoning was defined as :
Severe $\rightarrow$ serum acetylcholinesterase $<300$ IU/lit Moderate $\rightarrow$ serum acetylcholinesterase 300-600 IU/lit Mild $\rightarrow$ serum acetylcholinesterase 600-1500 IU/lit Very mild $\rightarrow$ serum acetylcholinesterase $>1500$ IU/lit

All patients were monitored closely and all clinical signs were assessed 12 hourly till complete recovery. Ventilatory support was considered in patients as and when required.

\section{Results}

Table 1: Table showing age and sex wise distribution in patients of organophosphorus poisoning

\begin{tabular}{|c|c|c|c|}
\hline \multirow{2}{*}{ Age group (years) } & \multicolumn{2}{|c|}{ Sex } & Total (\%) \\
\cline { 2 - 4 } & Male (\%) & Female (\%) & \\
\hline $11-20$ & $9(9 \%)$ & $7(7 \%)$ & $16(16 \%)$ \\
\hline $21-30$ & $28(28 \%)$ & $20(20 \%)$ & $48(48 \%)$ \\
\hline $31-40$ & $12(12 \%)$ & $9(9 \%)$ & $21(21 \%)$ \\
\hline$\geq 41$ & $13(13 \%)$ & $2(2 \%)$ & $15(15 \%)$ \\
\hline Total & 6 & 38 & 100 \\
\hline
\end{tabular}

In this study, $62 \%$ (62 cases) were male and $38 \%$ (38 cases) were female. The male to female ratio was 1.6:1.

Table 2: Table showing symptomatology in patients of organophosphorus poisoning

\begin{tabular}{|c|c|}
\hline Symptomatology & No. of cases (\%) \\
\hline Nausea \& vomiting & $86(86 \%)$ \\
\hline Pain in abdomen & $34(34 \%)$ \\
\hline Altered sensorium & $32(32 \%)$ \\
\hline Giddiness & $20(20 \%)$ \\
\hline Convulsion & $12(12 \%)$ \\
\hline Breathlessness & $21(21 \%)$ \\
\hline Salivation & $19(19 \%)$ \\
\hline
\end{tabular}

Nausea and vomiting were the commonest symptoms $86 \%$ of cases followed by pain in abdomen about $34 \%$ and altered sensorium in about $32 \%$ of cases. CNS manifestation in form of convulsion seen in $12 \%$. 


\section{International Journal of Science and Research (IJSR) \\ ISSN (Online): 2319-7064 \\ Index Copernicus Value (2013): 6.14 | Impact Factor (2015): 6.391}

Table 3: Table Showing signs in patients of organophosphorous poisoning

\begin{tabular}{|l|c|}
\hline Signs & No. of cases (\%) \\
\hline Typical smell in breath & $83(83 \%)$ \\
\hline Increased respiratory secretion & $19(18 \%)$ \\
\hline Tachypnea & $17(17 \%)$ \\
\hline & \\
\hline Bradycardia & $55 \%$ \\
\hline & \\
\hline Increased blood pressure & $9(9 \%)$ \\
\hline & \\
\hline Miosis & $42(42 \%)$ \\
\hline Disturbed consciousness & $52(52 \%)$ \\
\hline Fasciculation & $36(36 \%)$ \\
\hline
\end{tabular}

Typical smell in breath was seen in( $83 \%$ ) of cases, miosis in $(42 \%)$ of cases, disturbed consciousness in $(52 \%)$ of cases and fasciculations in $(36 \%)$. Respiratory failure in form of tachypnea, shallow respiration and bronchospasm were present in (17\%.). Cardiovascular menifestations in form of bradycardia was present in $55 \%$.

Table 4: Table showing relation of S. Acetylcholinesterase level and mortality

\begin{tabular}{|c|c|c|}
\hline $\begin{array}{c}\text { S. Acetylcholinesterase } \\
\text { (IU/L) }\end{array}$ & $\begin{array}{c}\text { No. of } \\
\text { patients (\%) }\end{array}$ & $\begin{array}{c}\text { No. of patients expired } \\
\text { (mortality) }(\%)\end{array}$ \\
\hline$<300$ & $3(3 \%)$ & $2(66 \%)$ \\
\hline $300-600$ & $5(5 \%)$ & $2(40 \%)$ \\
\hline $600-1500$ & $21(21 \%)$ & $10(47.6 \%)$ \\
\hline$\geq 1500$ & $71(71 \%)$ & $6(8.4 \%)$ \\
\hline
\end{tabular}

Highest mortality noted $(66 \%)$ in patients with lowest level of acetylcholinesterase (<300iu/l) . Among $71 \%$ (71 cases) with serum acetylcholinesterase level $\geq 1500$, only $8.4 \%$ (6 cases) mortality was noted. All patients with lowest level needed ventilator support $(100 \%)$.

Table 5: Table showing relation of time lag to treatment with mortality

\begin{tabular}{|c|c|c|}
\hline Time lag to treatment & No. of cases (\%) & Mortality (\%) \\
\hline$<1 \mathrm{hr}$ & $17(17 \%)$ & $1(5.88 \%)$ \\
\hline $1-4 \mathrm{hr}$ & $42(42 \%)$ & $4(9 \%)$ \\
\hline$\geq 4 \mathrm{hr}$ & $41(41 \%)$ & $15(36 \%)$ \\
\hline
\end{tabular}

The above table shows that 17 cases $(17 \%)$ presented in less than 1 hour and out of them, mortality was noted only in 1 patients $(5.88 \%) .4$ patients (9\%) expired among 42 patients (42\%) who received treatment within 1-4 hours of ingestion of poison, $41 \%$ of patients presented in more than 4 hours of ingestion of poison and among them 15 patients $(36 \%)$ expired.Our study shows that mortality was $100 \%$ in patients with GCS score between 3-6. 46.8\% mortality (15 patients) was seen in patients with GCS score between 7-10 and only $5.9 \%$ mortality (4 cases) was seen in patients with GCS score between 11-15.In present study, the mortality was high with lower GCS score.Our study also shows that 1 patient presented with GCS score between 3-6 and required ventilatory support. Among 32 patients who presented with GCS score between 7-10, 90.6\% (29 cases) required ventilatory support. 67 patients presented with GCS score between 11-15 and among them 19.4\% patients required ventilatory support. Level of serum acetylcholinesterase showing interesting reults.
Table 6: Table showing relation of pupil size with mortality

\begin{tabular}{|c|c|c|}
\hline \multirow{2}{*}{ Size of pupil (mm) } & Cases & Mortality \\
\cline { 2 - 3 } & No. & No. $\%$ \\
\hline$\leq 1$ & $21(21 \%)$ & $12(57.1 \%)$ \\
\hline $2-3$ & $32(32 \%)$ & $7(21.8 \%)$ \\
\hline$\geq 4$ & $47(47 \%)$ & $1(2.12 \%)$ \\
\hline
\end{tabular}

The above table shows that among 21 patients who presented with pupil size $\leq 1 \mathrm{~mm}$ the mortality rate was $57.1 \%$ ( 12 cases). Mortality rate was $21.8 \%$ ( 7 cases) among the 32 patients who presented with pupil size $2-3 \mathrm{~mm}$ and out of the 47 patients who presented with pupil size $\geq 4 \mathrm{~mm}$, mortality rate was $2.12 \%$ ( 1 case). The study also shown that higher initial requirement of atropine $(>60 \mathrm{mg})$ is seen in $25 \%$ of patients in whom ventilator requirement is also $\operatorname{high}(23 \%)$ as compared to low requirement $(18 \%)$ is associated with no requirement of ventilator.

\section{Conclusions}

- Poisoning are common cause of mortality in young adults. Identification of patients early may save the young life. Clinical history and examination with $n$ with cholinesrerese level can help to identify t.he patients at risk of mortality in organophosphras poisoning. In present study male versus female ratio was 1.6:1 which corresponds with the study by Tsao et $\mathrm{al}^{5}$, who found the ratio to be $1.2: 1$ and Friedman $\mathrm{LM}^{12}$ found the ratio to be 1.9:1 which had 64 males and 33 females. Alina Weissmann-Brenner ${ }^{3}$ in her study had male to female ratio of 1.9:1.

- In our study nausea and vomiting were the commonest symptoms.Altered sensorium was observed in $32 \%$ of cases comparable to Goel et al2. Which was $45 \%$ and $54 \%$ as per Tsoa et al 8 study.other symptoms were breathlessness,convulsion, giddiness...

- In our study miosis,disturbed consciousness, tachypnea,shallow respiration, fasciculation, bradycardia is noted comparable to Goel et al and Tsao et el study.

- In our study mortality was more i.e $66 \%$ with low serum cholinesterase level $<\mathbf{3 0 0}$ IU/lit comparable to Tsao et al study. In this study we observed that those patients who received treatment in lss than $1 \mathrm{hr}$, mortality was low comparable to Tsao et al study.

- In present study, miosis was observed in $42 \%$ of cases and it was in $95 \%$ of cases in the study done by Goel et $\mathrm{al}^{2}$. Tsoa et $\mathrm{al}^{5}$ in their study observed miosis in $83 \%$ of cases.

\section{References}

[1] Bardin PG, Stephan F. Van, Eeden John A Mullman et al : Organophosphate and carbamate poisoning.Arch.Intem.med. 1994; 154: 1433- 1441

[2] Goel A, S. Joseph \& TK Dutta : Organophosphate poisoning : Predicting the need for ventilatory support: JAPI: 1998:46:86-90

[3] Alina-Weissmann-Brenner IMAJ.Vol 4. July 2004

[4] Wadia RS, Chitra S, Amin RP et al : Electrophysiological studies in acute 


\section{International Journal of Science and Research (IJSR) \\ ISSN (Online): 2319-7064}

Index Copernicus Value (2013): 6.14 | Impact Factor (2015): 6.391

organophosphorous poisoning. J Neurol. Neurosurg Psychiatry. 1987; 50: 1442-48.

[5] Tsao TC, Yeong Chang Juang, Lan RS : Respiratory failure of acute organophoshpate and carbamate poisoning. CHEST: 1990: 98:631-635

[6] Taylor Palmer : Anticholinesterase agents, in Oilman AG Goodman LS eds. The pharmacological basis of therapeutics, 9th edition.

[7] Natrajan AR : Modi's Medical Jurisprudence, 20* edition; 5 1 7-570.

[8] Agarwal P, Wall JP : Organophosphate and carbamates : Diagnosis and management of common poisoning. Oxf. Uni. Press, 1997.

[9] Udwadia Faruk E : Critical care in poisonings. Principles of critical care, Oxf. Uni. Press, 1999.

[10] Agarwal SB : A clinical biochemical, neurobehavioural and sociophysiological study of 190 patients admitted to hospital as a result of acute Organophosphorous poisoning: Environ Res. 1998: 62.

[11] Sunder Ram J, Kumar SS, Yaymajan Kuppuswamy G : Continuous infusion of high doses of atropine in the management of Organophosphorous compound poisoning. JAPI; 39: 190-193.

[12] Friedman, LM, Isr. Med. Assoc J. 2005, Mar, 7(3): 207 